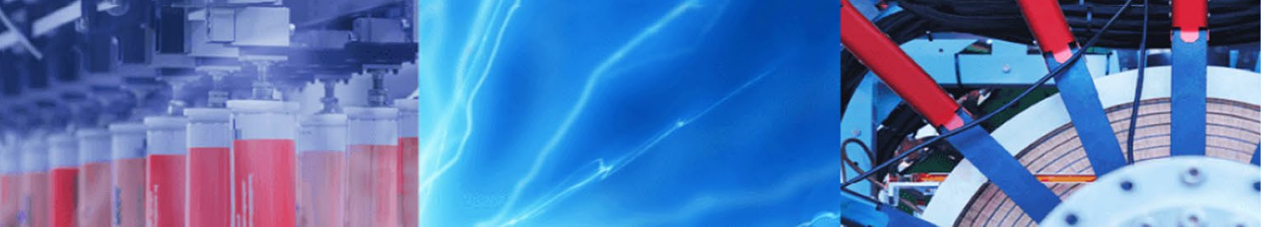

Research Article

\title{
Modelling and analysis of gradient effect on the dynamic performance of three-wheeled vehicle system using Simscape
}

\author{
Mohammad Waseem $^{1}$ (D) $\cdot$ Mohd Suhaib $^{2} \cdot$ Ahmad Faizan Sherwani $^{2}$
}

(c) Springer Nature Switzerland AG 2019

\begin{abstract}
In India, three-wheeled electric vehicles are one of the important modes of public transport in congested areas. The gradient is an important factor that affects the dynamic performance of the vehicle. The proposed work presents an extensive analysis of the gradient effects on the dynamic performance of a three-wheeled solar electric vehicle. Firstly, we have designed the physical vehicle model of three-wheeled using Simscape environment tool. The generated torque from "ideal torque source" block is transferred to the input drive shaft of the "differential" mechanism. The output drive shafts of "sun gears" or "differential" block are connected to the rear left as well as to the right wheels respectively. The "ideal translational motion sensor" subsystem block measures the speed and distance of the vehicle. Next, to examine the gradient effects and accuracy of the Simscape model, we have designed the longitudinal vehicle model of a threewheeled electric vehicle. Undertaken a comparative analysis of the Simscape models' results from the longitudinal vehicle model for three different road gradient condition having a slope of zero degrees $\left(0^{\circ}\right)$, six degrees $\left(6^{\circ}\right)$ and twelve degrees $\left(12^{\circ}\right)$ respectively.
\end{abstract}

Keywords Solar electric vehicles $\cdot$ Ideal torque source $\cdot$ Simscape $\cdot$ Longitudinal vehicle model

\section{Introduction}

Energy sources are the primary pillars for the survival of human beings in the current society. Presently, fossil fuel resources are responsible for $74 \%$ of the total global fuel consumption [1]. There is a global unbalance in supply and demand of the non-renewable resources and, this unbalance has led to severe environmental and energy deficiency situation worldwide [2]. Traditional vehicles consume excessive fossil fuel and enhance emissions of greenhouse gas [3,4]. The transportation division is major a contributor for $\mathrm{CO}_{2}$ emissions in India accounting approximately $18 \%$ of $\mathrm{CO}_{2}$ emissions [5]. At present, conventional resources of fuel are depleting, and the population is proliferating. Hence, available conventional sources are not sufficient to meet the future energy consumption [6].

In India, three-wheeled vehicles are the key modes of public transport in the metro cities, according to a report released by the Society of Indian Automobile Manufacturers (SIAM) [7]. Solar electric vehicles are considered a solution to decarbonise the automobile transportation sector $[8,9]$. Solar/battery electric vehicles provide improved transmission efficiency and cause quite less air, land and water pollution [10]. Solar electric vehicles (SEVs) have the exclusive potential to lessen the greenhouse gas emissions of the conservative vehicles [10-13]. Central government authorities have initiated various projects and research activities to improve the quality of the electric vehicle [14]. Electric vehicles have a completely different driving potential

\footnotetext{
$\checkmark$ Mohammad Waseem, waseem159088@st.jmi.ac.in; Mohd Suhaib, msuhaib@jmi.ac.in; Ahmad Faizan Sherwani, asherwani@jmi.ac.in | ${ }^{1}$ Department of Mechanical Engineering, Jamia Millia Islamia (A Central University), Jamia Nagar, New Delhi 110025 , India. ${ }^{2}$ Department of Mechanical Engineering, Faculty of Engineering and Technology, Jamia Millia Islamia (A Central University), Jamia Nagar, New Delhi 110025, India.
} 
mechanism as compared to the conventional one. In short, the electric potential stored in batteries is utilised to actuate the power drive system of electric vehicles [15-17]. The electric machine employed in the electric vehicle has the efficiency up to $95 \%$ while the efficiency of a gasoline engine is up to $35 \%$ [16]. Hence, the efficiency from the tank to the wheel of the electric vehicle is two times more. Thus, there is a need to research improving the mobility of electric vehicles.

Solar/battery electric vehicles are also considered 'green and clean' vehicles due to the advantages such as zero emissions, eco-friendly, improved transmission efficiency and light in weight $[18,19]$. Various aspects of electric vehicles are proposed in contemporary literature, but none have reported the Simscape model of a vehicle [20-22]. A rough overview of solar passenger van is proposed in the literature without accurate dynamic modelling by Tarek et al. [23, 24]. Tang et al. [25] provided vibrational modelling of fourwheeler electric vehicle. However, no research is reported on three-wheeled vehicles for its mobility design and the effects of the gradient on the dynamic performance of the three-wheeled electric vehicle.

\section{Methodology}

The work discussed above suggests that battery/solar vehicles are conceived as "the vehicles of future" in the queue of conventional ones. Simscape is the fundamental tool to design and simulate the virtual model of various engineering problems before investing to make the actual prototype.

In the present work, the effect of gradient levels on the dynamic performance of a three-wheeled vehicle is analysed. The physical vehicle model of three-wheeled electric vehicle is designed in the Simscape environment of MATLAB ${ }^{\circ}$ tool. Next, the physical signal of the torque to the left and right wheel is transferred with the help of "ideal torque source" and "differential" blocks. Thereafter, to cross-check the Simscape physical model, longitudinal vehicle model is developed. After that, determine the appropriate mechanical parameters and coefficients from the literature survey. Finally, compared Simscape physical model results with a longitudinal model for three road gradient conditions. Figure 1 shows the SolidWorks model structure of the proposed solar electric vehicle. In the next section, we have discussed the Simscape physical dynamic model of threewheeled solar/battery electric vehicle.

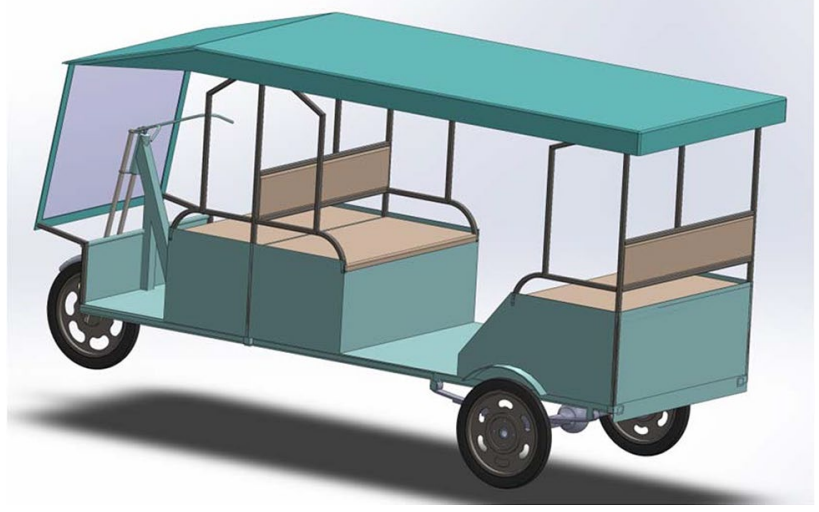

Fig. 1 SolidWorks model structure of the proposed three-wheeled vehicle

\section{Physical modelling of the three-wheeled vehicle using Simscape tool}

Simscape is the fundamental library tool of MATLAB ${ }^{\circ}$ software to design and simulate interdisciplinary engineering problems. In research and development, the Simscape is also playing an essential role in designing and simulating multi-disciplinary task effectively. Physical vehicle model of three-wheeled solar vehicle is designed and developed in the Simscape environment library of MATLAB ${ }^{\circ}$ software.

Figure 2 shows the developed Simscape physical dynamics model of the proposed three-wheeled electric vehicle.

\subsection{Description and physical significance of physical vehicle model blocks}

The physical vehicle model consists of various physical block and subsystem such as ideal torque source, mechanical differential gear, vehicle subsystem, ideal rotational motion sensors and Simulink scopes. The description and physical significance of blocks employed in the Simscape physical vehicle model are discussed below:

\subsubsection{Ideal torque source}

The ideal torque source is an ideal source of mechanical energy and generates torque proportional to the input physical signal or its' profile. The Fig. 2 shows that the block of "Ideal torque source" consists of three ports or connections namely $S, C$ and $R$. These ports are the input and output gates to execute the command through the physical signal. 


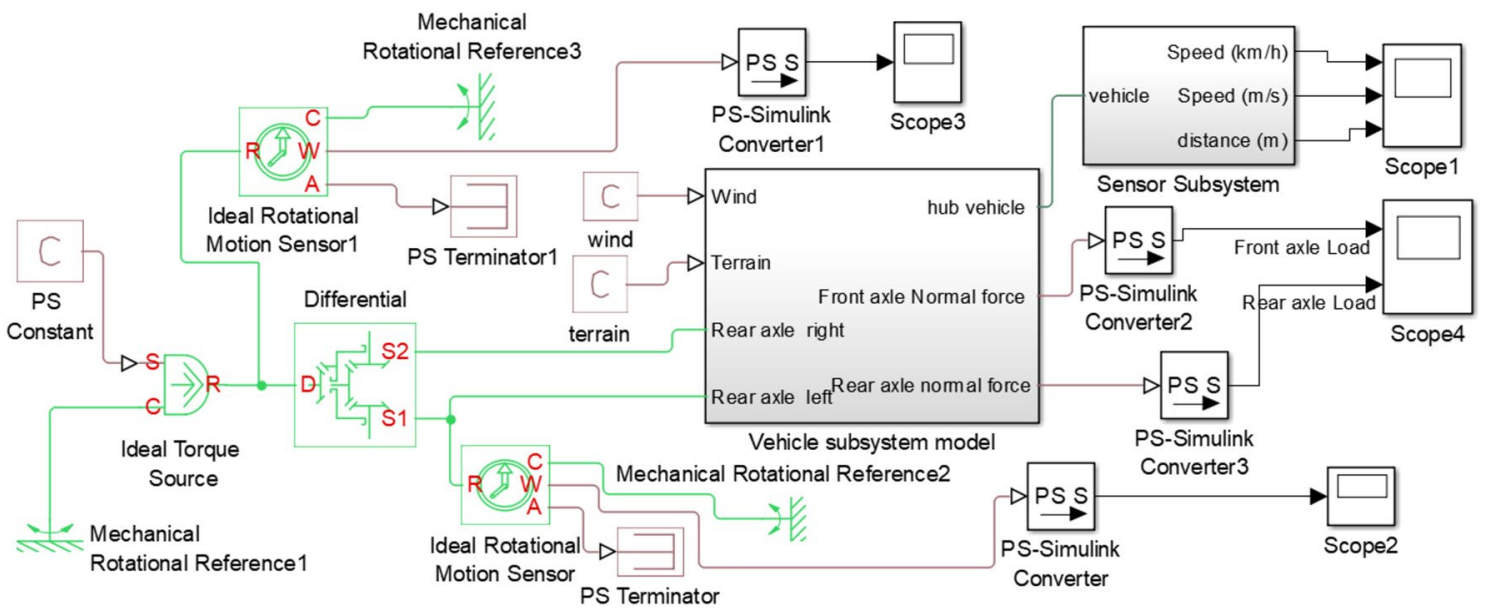

Fig. 2 Overall physical vehicle model prepared in Simscape environment of the proposed three-wheeled vehicle model

Ports S, C and R of the "ideal torque source block" are associated to specify input and output physical signal. The mechanical rotational conserving port $C$ associated with the ideal torque source is connected to the mechanical rotational reference. The physical signal port S of "ideal torque source" block associated to specify the control torque value or profile is connected to "PS Constant" block. The output mechanical rotational port R of "Ideal torque source" is connected to the input driveshaft or port D of the "differential" block.

\subsubsection{Differential block}

The Fig. 2 shows that the "differential" block of Simscape model consists of three ports namely D, S1 and S2 for the physical input and output signal command. The ports S1 and S2 of "differential" block are associated with the left and right sun gears output shafts respectively and connected to the rear left as well as the right axle of the wheel. The output driven shafts of the "differential" block are connected to the rear left and right wheels to impart motion. Hence, the differential block represents a gear mechanism that permits driven shafts to rotate at different speeds.

\subsubsection{Ideal rotational motion sensor}

The Fig. 2 shows that the "ideal rotational motion sensor" block of Simscape vehicle model consists of four connections namely $\mathrm{R}, \mathrm{C}, \mathrm{W}$ and $\mathrm{A}$ to measure the physical signal of angular velocity. The connections $R$ and $C$ of "ideal rotational motion sensor" block are mechanical rotational conserving ports. Connections W and A of "ideal rotational motion sensor" block are output physical signal ports to measure the angular velocity and displacement respectively.
Ideal rotational motion sensor blocks are employed to measure the rotational speed of output shafts connected to ideal torque source and differential respectively. The ideal rotational motion sensor represents a device that converts an across variable measured between two mechanical rotational nodes into a control signal. The measured variable of the control signal is directly proportional to the angular velocity or angle.

\subsubsection{PS constant block}

The "PS constant" block generates a physical signal or control profile of constant value. The Fig. 2 shows that the "PS Constant" block is connected to $S$ port of the "Ideal torque source" block to specify the torque value.

\subsubsection{Mechanical rotational reference}

The "mechanical rotational reference" block act as a reference point or frame (ground) for all mechanical rotational ports that are rigidly clamped. The Fig. 2 shows that the "mechanical rotational reference" blocks relate to $C$ port of the "ideal torque source" and "ideal rotational motion sensor" respectively for grounding.

\subsubsection{PS Terminator}

The function of "PS Terminator" block is to terminate the output physical signal or to indicate that the signal was not inadvertently left unconnected. The Fig. 2 shows that "PS Terminator" block is connected to A port of "Ideal rotational motion sensor" block for terminate the output physical signal. 


\subsubsection{PS-Simulink converter}

The working of the "PS-Simulink" block is to convert the physical signal into a Simulink signal for simulation. The Fig. 2 shows that the "PS-Simulink" block is connected to W port of the "ideal rotational motion sensor" block.

\subsubsection{Scope}

The "Simulink Scope" block acts as "Sink" to displays time domain signals with respect to the simulation time. The Fig. 2 shows that four "scope" blocks are employed to analyse the signal during simulation.

\subsection{Vehicle subsystem model}

Vehicle subsystem is an integral part of the overall physical vehicle model. Figure 3 shows the inside open view of vehicle subsystem model. The physical model of vehicle subsystem consists of blocks such as the vehicle body, rear left tire, rear right tire, front tire, Physical-Simulink converter and several connections ports. The description and physical significance of blocks employed in the vehicle subsystem model are as follows.

\subsubsection{Vehicle body}

Figure 3 shows that W, V, H NR, NF and beta are the six input and output physical signal ports or connections of the "vehicle body" block. Connections beta and W of the "vehicle body" block are the physical signal input ports associating to the road inclination angle and headwind speed respectively. Connections NF, NR and V of vehicle body block are the physical signal output ports associated with normal force on the front wheel, rear wheel and velocity of the vehicle respectively. Connection $\mathrm{H}$ of the "vehicle body" block is a translation conserving port associated with the horizontal movement.

The "vehicle body model" block represents a two-axle vehicle along longitudinal dynamics, adjustable mass, drag properties, motion, and geometry. The axles have different wheel counts and same wheel in case of twowheel per axle.

\subsubsection{Tire block (magic formula)}

Figure 3 shows that $\mathrm{S}, \mathrm{N}, \mathrm{A}$ and $\mathrm{H}$ are the input and output physical signal ports of each "tire block" for Simscape vehicle model. Connection $\mathrm{N}$ of tire block is associated with a normal input force on the tire. Connection $\mathrm{N}$ of the rear left, and right tire blocks are connected to NR port of vehicle body. Connection $\mathrm{N}$ of front tire block relates to port NF of the vehicle body. Connection A of rear wheel tire block belongs to the mechanical rotational port associated with the axle of the tire and connected to the differential gear. $\mathrm{H}$ port of all tires is associated with machine translation and connected with $\mathrm{H}$ port of the vehicle body. Port $\mathrm{S}$ of all tire blocks are associated with the slip between tire and road is connected to PS Terminator block.

The three-wheeled vehicle having the configuration of one front wheel and two rear wheels are considered for the present work. Magic formula tire block that represents a model of a tire with longitudinal behaviour given by an empirical equation based on four fitting coefficients is employed for Simscape vehicle modelling.

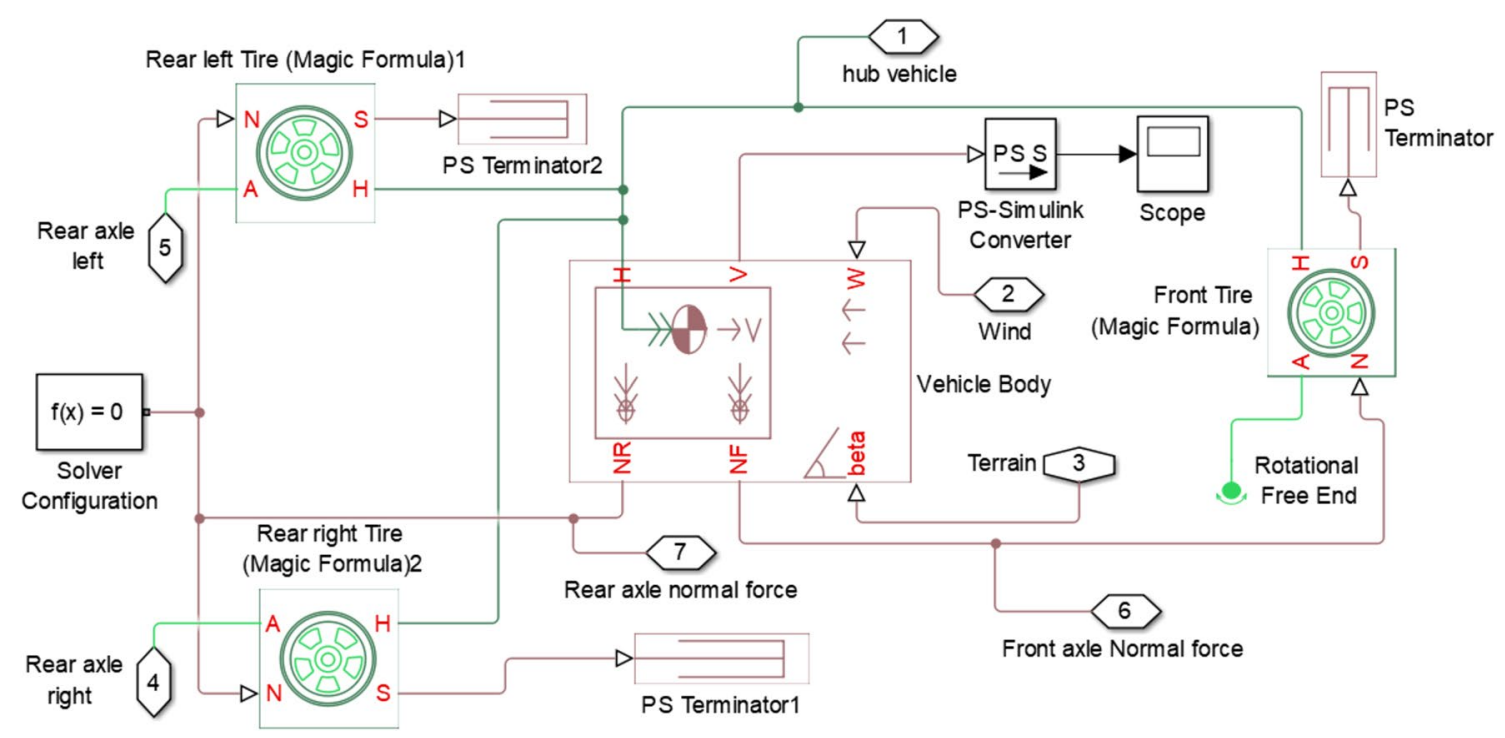

Fig. 3 Simscape vehicle subsystem model of the proposed three-wheeled solar vehicle 


\subsubsection{PS Terminator}

The function of the "PS Terminator" block is to terminate the output physical signal or to indicate that the signal was not inadvertently left unconnected. Figure 3 shows that "PS Terminator" block is connected to S port of the "Rear left tire", "Rear right tire" and "front tire" block respectively.

\subsubsection{Rotational free end}

The "Rotational free end" block represents mechanical rotational port terminator with zero torque or rotates freely without any torque. Figure 3 shows that the "rotational free end" block is connected to port A of the "front tire" block.

\subsubsection{Solver configuration}

Each physical Simscape ${ }^{\mathrm{TM}}$ block Network requires exactly one "Solver Configuration" block to be connected to specifies the solver parameters that your model needs before you can begin the simulation. Figure 3 shows that one "Solver Configuration" block is connected for simulation.

\subsubsection{Connection ports}

The "connection port" block is a physical modelling connection for the subsystem. Figure 2 and 3 show that seven connection ports are associated with "vehicle subsystem" block. The "connection port" block has the flexibility to specify its location on the parent subsystem either "left" or "right".

\subsection{The sensor subsystem (Ideal translation motion sensor) block}

The Fig. 4 shows that the "ideal Translation motion sensor" block of the vehicle model consists of four connections namely $R, C, V$ and $P$ to measure the physical signal of the velocity and position. The connections $R$ and $C$ of "ideal translational motion sensor" block are mechanical translational conserving ports. Ports $C$ and $R$ connects "ideal Translation motion sensor" block to the nodes whose motion is being monitored. Connections V and P of "ideal Translation motion block" are output physical signal ports to measure the velocity and position respectively.

Figure 4 shows that two "PS-Simulink Converter" blocks are employed to convert the output physical signal of speed from connection $V$ into the Simulink signal. The third "PS-Simulink Converter" block converts the physical signal of position into the Simulink signal. The "connection port" blocks of speed $(\mathrm{km} / \mathrm{h})$, speed $(\mathrm{m} / \mathrm{s})$ and distance $(\mathrm{m})$ are connected to the "scope" block.

\subsection{Working with the physical vehicle model}

The generated torque from "ideal torque source" block is transferred to the input drive shaft of the "differential" block. The output driveshafts of "differential" block are connected to the rear left as well as to the right wheels respectively. Hence, the torque from "differential" block is transferred to the "rear left" and "rear right" wheels. The "PS-Simulink Converter" converts the physical signal of the load acting on the "front" and "rear" axle into Simulink" scope. The "ideal translational motion sensor" subsystem block measures the speed and distance of the vehicle. The physical model of threewheeled vehicle is compiled in Simscape environment to
Fig. 4 Block diagram of an ideal translation motion sensor subsystem of the proposed Simscape vehicle model

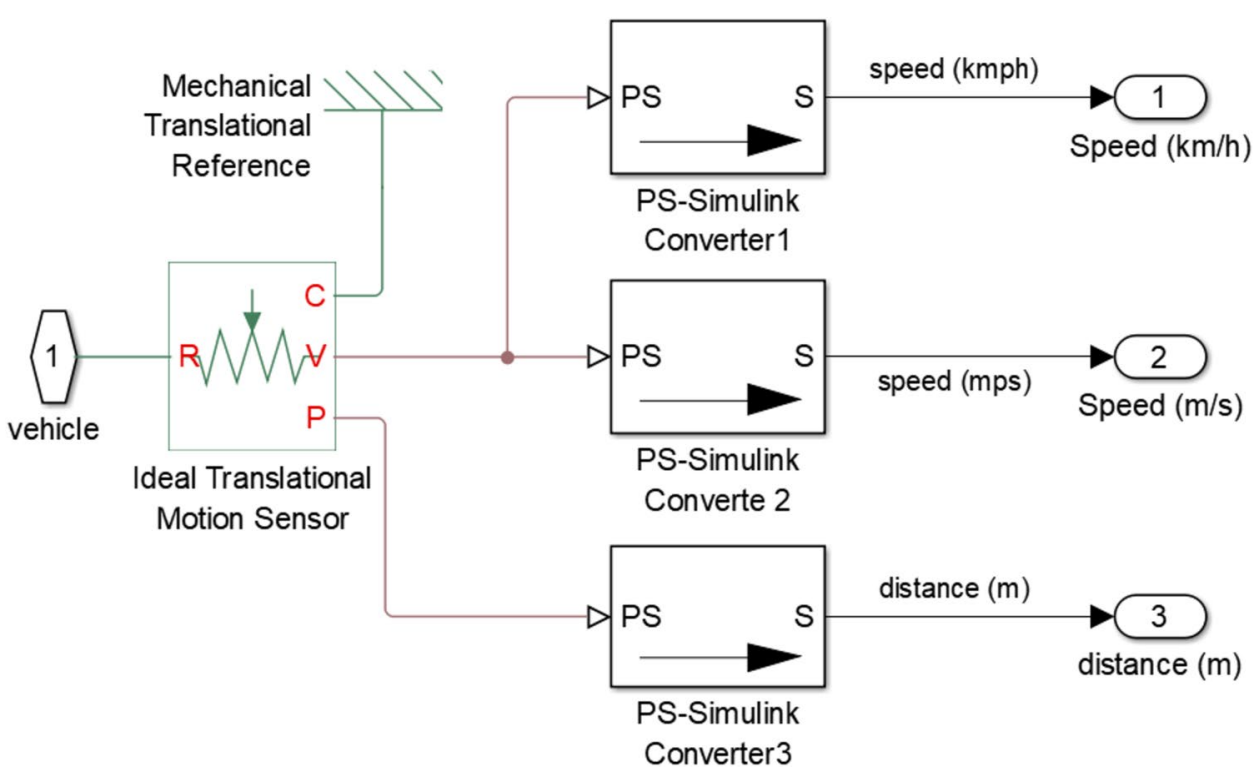

SN Applied Sciences 
check the error between the connections. In the next section, the longitudinal dynamics model of a three-wheeled vehicle is presented.

\section{The longitudinal model of three-wheeled electric vehicle}

The movement deportment of the vehicle in the moving direction is determined by the forces acting in that particular direction [26]. The forces and moments are acting on the vehicle in the longitudinal direction for road having a positive slope (a) shown in Fig. 5. Drag due to air $\left(F_{\text {drag }}\right)$, rolling resistance between tire-road contact $\left(F_{\text {roll }}\right)$ and resistance to the gradient $\left(F_{\text {grad }}\right)$ are the external driving obstacles acting on the electric vehicle in the longitudinal direction. Tractive effort $\left(F_{\text {Tractive }}\right)$, acts in the longitudinal direction to move the vehicle, is transmitted through the electrical actuating system. According to Newton Second Laws of motion, the mathematical expression between forces and acceleration in the longitudinal direction (X-direction) of the vehicle is given by Eq. (1).

$F_{\text {Tractive }}=\lambda M \frac{d V_{X}}{d t}+\sum F_{\text {Resistive }}$

where $F_{\text {Tractive }}$ is total tractive effort acting on the wheel of a vehicle in a longitudinal direction, $M$ is the total mass of the solar electric vehicle, $\lambda$ is a factor of rotating mass.

The electric propulsion or actuating system imparts the necessary tractive torque to move the vehicle with acceleration $d V_{X} / d t$ as well as to overtake the resistance forces. The composition of all the resistive forces acting on the electric vehicle in the longitudinal direction [please see Eq. (2)].

$$
\sum F_{\text {Resistive }}=\underbrace{M g \sin \alpha}_{\text {grade }}+\underbrace{M g \mu_{r} \cos \alpha}_{\text {roll }}+\frac{1}{2} \underbrace{\rho A_{f} C_{D} V_{x}^{2}}_{\text {drag }}
$$

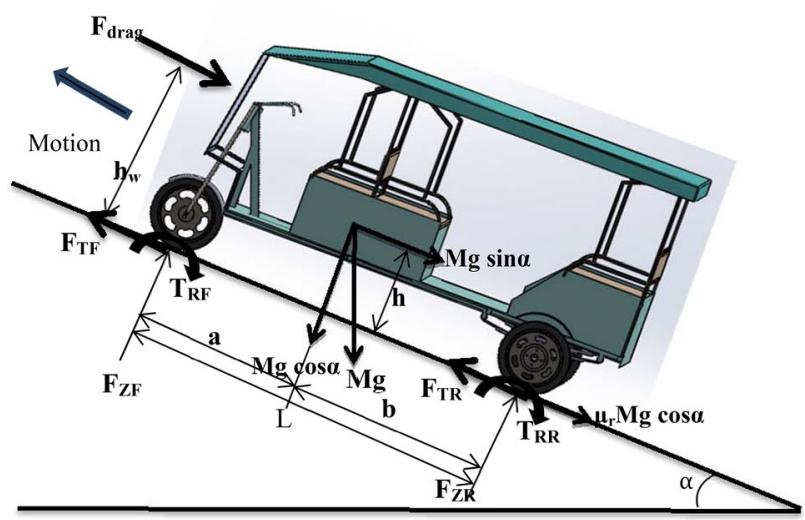

Fig. 5 Forces and Torques acting on the proposed three-wheeled vehicle model on an inclined road

SN Applied Sciences where $g$ is the gravitational constant, $a$ is the slope of the road, $\mu_{r}$ is the frictional coefficient due to rolling between the contact point of tire and road, $\rho$ is the density of air, $A_{f}$ is the front area of vehicle, $C_{D}$ is the coefficient of drag due to air and $V_{X}$ is the longitudinal velocity of the vehicle. Equation (3) gives the tractive effort acting on the vehicle in the longitudinal direction.

$F_{\text {Tractive }}=\lambda M \frac{d V_{x}}{d t}+\underbrace{M g \sin \alpha}_{\text {grade }}+\underbrace{M g \mu_{r} \cos \alpha}_{\text {roll }}+\frac{1}{2} \underbrace{\rho A_{f} C_{D} V_{x}^{2}}_{\text {drag }}$

The normal dynamic load acting in the vertical direction on the front axle can be determined by taking moments of forces acting on the vehicle about contact point of tire and road as given below Eqs. (4) and (5).

$F_{Z F} L=M g b \cos \alpha-\left(T_{R F}+T_{R R}+F_{d r a g} h_{w}+M g h \sin \alpha+\lambda h M d V_{x} / d t\right)$

Taking, $h_{w} \approx h$,

$F_{Z F}=\frac{M g b \cos \alpha}{L}-\frac{1}{L}\left(T_{R F}+T_{R R}+F_{d r a g} h+M g h \sin \alpha+\lambda h M d V_{X} / d t\right)$

Total rolling resistance moment $\left(T_{R F}+T_{R R}\right)$ acting between wheel and ground is equal to the product of equivalent force (rolling resistant force) and radius of the tire. Mathematically, rolling resistance moments is given by Eq. (6).

$T_{R F}+T_{R R}=\mu_{r} M g r_{w} \cos \alpha$

where $M g$ is total weight acting at the centre of the wheel, $\mu_{r}$ is the coefficient of friction between tire and ground, $r_{w}$ is the effective radius of the wheel. Hence, the normal load acting on the front axle is governed by Eq. (7).

$F_{Z F}=\frac{M g b \cos \alpha}{L}-\frac{h}{L}\left(F_{\text {Tractive }}-\mu_{r} M g \cos \alpha\left(1-\frac{r_{w}}{h}\right)\right)$

Similarly, Eq. (8) expresses the normal load acting in the vertical direction on the rear axle).

$F_{Z R}=\frac{M g a \cos \alpha}{L}+\frac{h}{L}\left(F_{\text {Tractive }}-\mu_{r} M g \cos \alpha\left(1-\frac{r_{w}}{h}\right)\right)$

The tractive torque acts on the wheel of an electric vehicle in the longitudinal direction, (along $\mathrm{X}$-axis) is equal to the product of tractive effort acting on the wheel and effective radius of the wheel. The necessary tractive torque acting on the wheel of the vehicle comes from the electric propulsion system. Mathematically expression for tractive torque ( $\left.T_{\text {tractive }}\right)$ acting on the wheels of the solar electric vehicle is given by Eq. (9). 
$T_{\text {tractive }}=(\lambda M \frac{d V_{X}}{d t}+\underbrace{M g \sin \alpha}_{\text {grade }}+\underbrace{M g \mu_{r} \cos \alpha}_{\text {roll }}+\frac{1}{2} \underbrace{\rho A_{f} C_{D} V_{X}^{2}}_{\text {drag }}) r_{w}$

Several mechanical design parameters and coefficients are associated with the tractive effort $\left(F_{\text {Tractive }}\right)$ as expressed in Eq. (3), the vertical force acting on the front $\left(F_{Z F)}\right.$ and rear axle $\left(F_{Z R}\right)$ given in Eqs. (7) and (8) as well as tractive torque ( $\left.T_{\text {tractive }}\right)$ acting on the wheel as expressed in Eq. (9). Hence, accurate estimation of the tractive effort, the load on the front axle and tractive torque acting on the wheel of the vehicle require sensitive selection of designing parameters and coefficients.

\section{Parameters selection for the proposed model of three-wheeled electric vehicle}

Mechanical parameters and coefficients play a crucial role in designing and modelling the tractive effort and torque for an electric vehicle. Therefore, there is a need to survey the literature and work associated with vehicles parameter. Work related to mechanical vehicle parameters are discussed below, and the appropriate value of parameter and coefficient is considered for designing of present vehicle to avoid errors and conflicts.

\subsection{The coefficient of friction $\left(\mu_{r}\right)$}

The coefficient of friction $\left(\mu_{r}\right)$ is a function of the tire and road surface condition. It depends on the deformation effect of the tire [26]. The tire deformation is associated with several characteristics such as the type of tire, pressure, temperature, the macrotexture asphalt of tire and velocity of the vehicle. The rolling frictional lies in the range of 0.007-0.015 for all passenger cars according to the Board of transportation research [27]. We have considered 0.015 for the design of the proposed vehicle.

\subsection{The coefficient drags due to air $\left(C_{D}\right)$}

The coefficient drags due to air $\left(C_{D}\right)$ for passenger automobile vehicles lies in the range $0.24-0.38$ for Tesla Model $S$ and Subaru Forester respectively. However, various vehicles have an additional $6 \%$ uncertainty range in air drag coefficient [28]. Furthermore, not only the value of drag coefficient depends on vehicle shape some other features also influences the air drag such as the condition of windows and angle of air attack. Hence, for the present work, we have considered the limit value 0.333 of the coefficient of drag.

\subsection{The factor of rotating mass $(\lambda)$}

The factor of rotating mass $(\lambda)$ is the inertia of rotating parts or components such as motors, transmission system and wheels. Nandi et al. [29] considered this factor value as 1.0 for their proposed work. While Ehsani et al. [26] and Maya et al. [30] have been taken mass factor as 1.05 for the proposed work. The range of this factor lies from 1 to 1.05. The factor value 1.05 is considered for present work.

\subsection{The density of air ( $\rho)$}

The density of air ( $\rho$ ) of any fluid plays an essential part in deciding the resistance of a body moving into that fluent. According to DeNysschen, the air density can be computed on-line based on the following parameters: the altitude, the humidity and the temperature of the atmosphere [31]. The numerical range of air density for electric vehicles is 1.055 to $1.246 \mathrm{~kg} \mathrm{~m}^{3}$ having the altitude ranges $100-700 \mathrm{~m}$, the temperature ranges $-5^{\circ}$ to $30^{\circ} \mathrm{C}$ and the humidity ranges $65-70 \%$. In the presented work, $1.22 \mathrm{~kg} \mathrm{~m}^{3}$ the density of air is considered.

\subsection{The front area of the three-wheeled vehicle $\left(A_{f}\right)$}

The front area of the vehicle $\left(A_{f}\right)$ can be calculated as the multiplication of width and height. Asamer et al. [32] suggested an approximation to compute the frontal area of the vehicle as a product of height and width. Thus, the frontal area for the proposed vehicle is taken as $1.75 \mathrm{~m}^{2}$.

\subsection{The efficiency of the drivetrain $\left(\eta_{M}\right)$}

The electric motor generates torque to move the vehicle. The differential transmits this generated torque to the wheels. The overall effeteness of the drive train is the multiplication of the battery efficiency $\eta_{\text {battery }}$, motor efficiency $\eta_{\text {motor }}$ and mechanical transmission efficiency $\eta_{\text {transmission on }}$ [33]. The overall efficiency of the drive train varies between 0.63 and 0.90 [33]. The maximum value of 0.9 of $\eta_{M}$ is considered for this study.

\subsection{The speed of the three-wheeled vehicle $\left(V_{x}\right)$}

International Centre for Automotive Technology (ICAT) approves the speed of three-wheeled e-rickshaw/e-cart models in range 11.67-25.00 km/hour [34]. Hence, $25 \mathrm{~km} /$ hour maximum speed is considered for the present work model of a three-wheeled vehicle. 


\subsection{The weight of the three-wheeled vehicle (M)}

The vehicles' design parameters such as weight, wheelbase, the diameter of the wheel, the distance between C.G and front axle are considered based on the three-wheeled e-rickshaw vehicles' model of Saera Electric Auto Pvt. Ltd. [35], Kuku Automotive [36], Goenka Electric Motor Vehicles etc. $[37,38]$.

Appropriate mechanical parameter and coefficient considered for present vehicle designing and modelling are summarised in Table 1.

Mechanical parameters and coefficients discussed above are employed in the Simscape and longitudinal vehicle models. Simulated results and analytical results are discussed in the next section.

\section{Results}

The dynamic performance of the three-wheeled vehicle is analysed for gradient levels of $0^{\circ}, 6^{\circ}$ and $12^{\circ}$ respectively. The effects of gradient levels on dynamic performance for Simscape physical vehicle model, longitudinal vehicle model and the comparison between these models are given below in the following sub-sections:

\subsection{The effect of gradient levels for Simscape physical vehicle model}

Firstly, the physical vehicle dynamic model of threewheeled solar electric vehicle is developed in Simscape environment tool. Next, appropriate mechanical parameter and coefficient considered for modelling of the present vehicle are assigned to the developed Simscape physical vehicle model. After that, simulations of the physical vehicle model have been carried out in the Simscape environment to analyse the effect of gradient levels of $0^{\circ}, 6^{\circ}$ and $12^{\circ}$ respectively.

Table 2 given below shows the simulated/computed values of parameters from the Simscape physical vehicle model for each road having of $0^{\circ}, 6^{\circ}$ and $12^{\circ}$ of the slope.

The simulated result signifies that the magnitudes of the applied torque on the wheel are 109.035, 239.15 and 367.589 for gradient levels of $0^{\circ}, 6^{\circ}$ and $12^{\circ}$ respectively. Further, the computed results show that torque applied to the wheel for the gradient level $12^{\circ}$ is more than three
Table 1 Mechanical designing parameters of the threewheeled solar electric vehicle

Table 2 Simscape results of the physical vehicle model

\begin{tabular}{llcl}
\hline S. No. & Design parameters & Design value & SI unit \\
\hline 5.1 & The rolling friction coefficient $\left(\mu_{r}\right)$ & 0.015 & \\
5.2 & The drag coefficient $\left(C_{D}\right)$ & 0.333 & \\
5.3 & The mass factor of Rotation $(\lambda)$ & 1.000 & \\
5.4 & The air density $(\rho)$ & 1.220 & $\mathrm{~kg} / \mathrm{m}^{3}$ \\
5.5 & The Front area of the three-wheeled vehicle $\left(A_{f}\right)$ & 1.750 & $\mathrm{~m}^{2}$ \\
5.6 & The overall efficiency of the drivetrain $\left(\eta_{M}\right)$ & 0.900 & \\
5.7 & The speed of the three-wheeled vehicle $\left(V_{X}\right)$ & 25.000 & $\mathrm{~km} / \mathrm{h}$ \\
5.8 & The estimated weight of the vehicle $(M)$ & 500.0 & $\mathrm{Kg}$ \\
5.9 & Wheel Diameter of vehicle $\left(d_{w}\right)$ & 0.508 & $\mathrm{~m}$ \\
5.10 & The wheelbase of the three-wheeled vehicle $(L)$ & 2.200 & $\mathrm{~m}$ \\
5.11 & The distance between vehicle C.G. and front axle $(a)$ & 1.000 & $\mathrm{~m}$ \\
5.12 & The distance between vehicle C.G. and rear axle $(b)$ & 1.200 & $\mathrm{~m}$ \\
\hline
\end{tabular}

\begin{tabular}{|c|c|c|c|c|}
\hline \multirow[t]{2}{*}{ Road slope (a) } & \multicolumn{2}{|c|}{ Simscape input variables } & \multicolumn{2}{|c|}{ Simscape output variables } \\
\hline & Input variable & Numerical value & Output variables & Numerical value \\
\hline \multirow[t]{3}{*}{$0^{\circ}$} & Applied torque & $109.035(\mathrm{~N}-\mathrm{m})$ & Longitudinal velocity & $25(\mathrm{~km} / \mathrm{h})$ \\
\hline & & & Load on the front axle & $2.627(\mathrm{kN})$ \\
\hline & & & Load on the rear axle & $2.2782(\mathrm{kN})$ \\
\hline \multirow[t]{3}{*}{$6^{\circ}$} & Applied torque & $239.18(\mathrm{~N}-\mathrm{m})$ & Longitudinal velocity & $25(\mathrm{~km} / \mathrm{h})$ \\
\hline & & & Load on the front axle & $2.5425(\mathrm{kN})$ \\
\hline & & & Load on the rear axle & $2.3360(\mathrm{kN})$ \\
\hline \multirow[t]{3}{*}{$12^{\circ}$} & Applied torque & $367.589(\mathrm{~N}-\mathrm{m})$ & Longitudinal velocity & $25(\mathrm{~km} / \mathrm{h})$ \\
\hline & & & Load on the front axle & $2.4295(\mathrm{kN})$ \\
\hline & & & Load on the rear axle & $2.3684(\mathrm{kN})$ \\
\hline
\end{tabular}


times compared to $0^{\circ}$. The percentage increment in the load acting on the rear wheel is $4 \%$ for the gradient level $12^{\circ}$ as compared to $0^{\circ}$. Hence, the gradient level is a crucial factor affecting the dynamic performance of the three-wheeled vehicle.

\subsection{Longitudinal results of the vehicle model}

The designing and modelling equations of tractive effort, the normal load, acting on the front as well as rear axle and tractive torque acting on the wheel of the longitudinal vehicle model, are coded in MATLAB ${ }^{\circ}$ programming environment. Next, appropriate mechanical parameters and coefficients data of Table 1, considered for designing present vehicle are assigned in the coded equations. Finally, the tractive effort, the load on axles and tractive torque on the wheel of longitudinal vehicle model are computed for $0^{\circ}, 6^{\circ}$ and $12^{\circ}$ road gradient conditions respectively. Figure 6 shows the variation in a torque acting on the wheel of longitudinal vehicle model at $0^{\circ}$ gradient of the road.

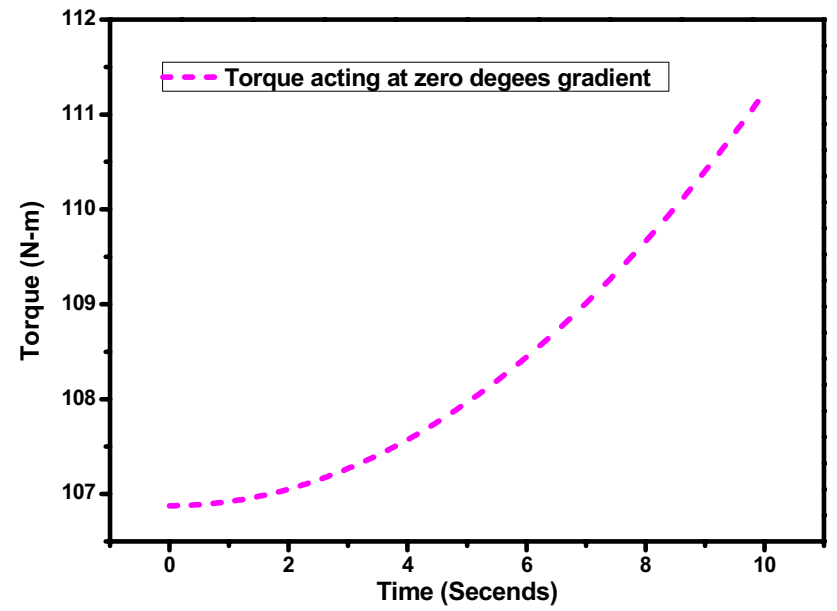

Fig. 6 Tractive torque acting on the wheel axle of the longitudinal vehicle model
Figure 6 signifies that the torque applied to the wheel varies from an initial value of $106.876 \mathrm{~N}-\mathrm{m}$ to final value $111.430 \mathrm{~N}-\mathrm{m}$ through 201 intermediate values. Hence, computed data is further post-processed to predict the effect of gradient levels on the dynamic performance of the three-wheeled vehicle. Average value of the torque applied on wheel, the dynamic load acting on the front as well as rear axles are computed. Table 3 shows the input and output parameters of longitudinal vehicle model for road having a slope of $0^{\circ}, 6^{\circ}$ and $12^{\circ}$ respectively.

The computed values of output variables from the longitudinal vehicle model result show that the tractive torque acting on the wheel increases as the slope of the road increases. The numerical magnitudes of tractive torque acting on the wheel are 108.3317, 238.4582 and $366.9543(\mathrm{~N}-\mathrm{m})$ for road having a slope of $0^{\circ}, 6^{\circ}$ and $12^{\circ}$ respectively to attain $25 \mathrm{~km} / \mathrm{h}$ of longitudinal velocity. Again, the computed results show that tractive torque acting on the wheel for the gradient level $12^{\circ}$ is more than three times compared to $0^{\circ}$ for the longitudinal model. The percentage increment in the load acting on the rear wheel is approximately $4 \%$ for the gradient level $12^{\circ}$.

\subsection{Validation through comparison between results obtained by Simscape physical and longitudinal models}

The results of the Simscape model are compared with the results of the longitudinal model for three gradient condition of the road having a slope of $0^{\circ}, 6^{\circ}$ and $12^{\circ}$ respectively. Figures 7,8 and 9 show the computing error/difference between the result values of the applied torques, the load acting on the front and the rear axles for Simscape and longitudinal model.

Figure 7 shows the result values of applied torques for Simscape and longitudinal model at the gradient levels of $0^{\circ}, 6^{\circ}$ and $12^{\circ}$ respectively. Above figure signifies that there is a minor difference between the result values of torques for Simscape and longitudinal model. Hence, the
Table 3 Longitudinal vehicle model result

\begin{tabular}{|c|c|c|c|c|}
\hline \multirow[t]{2}{*}{ Road slope (a) } & \multicolumn{2}{|l|}{ Input variables } & \multicolumn{2}{|l|}{ Output variables } \\
\hline & Variable's name & Assigned value & Variable's name & Computed mean value \\
\hline \multirow[t]{3}{*}{$0^{\circ}$} & Vehicle velocity & $25(\mathrm{~km} / \mathrm{h})$ & Tractive Torque & $108.3317(\mathrm{~N}-\mathrm{m})$ \\
\hline & Acceleration & $0.6944\left(\mathrm{~m} / \mathrm{s}^{2}\right)$ & Load on front axle & $2.6188(k N)$ \\
\hline & & & Load on the rear axle & $2.2862(\mathrm{kN})$ \\
\hline \multirow[t]{3}{*}{$6^{\circ}$} & Vehicle velocity & $25(\mathrm{~km} / \mathrm{h})$ & Tractive Torque & $238.4582(\mathrm{~N}-\mathrm{m})$ \\
\hline & Acceleration & $0.6944\left(\mathrm{~m} / \mathrm{s}^{2}\right)$ & Load on front axle & $2.5343(\mathrm{kN})$ \\
\hline & & & Load on the rear axle & $2.3438(\mathrm{kN})$ \\
\hline \multirow[t]{3}{*}{$12^{\circ}$} & Vehicle velocity & $25(\mathrm{~km} / \mathrm{h})$ & Tractive Torque & $366.9543(\mathrm{~N}-\mathrm{m})$ \\
\hline & Acceleration & $0.6944\left(\mathrm{~m} / \mathrm{s}^{2}\right)$ & Load on front axle & $2.4215(\mathrm{kN})$ \\
\hline & & & Load on the rear axle & $2.3763(\mathrm{~N})$ \\
\hline
\end{tabular}




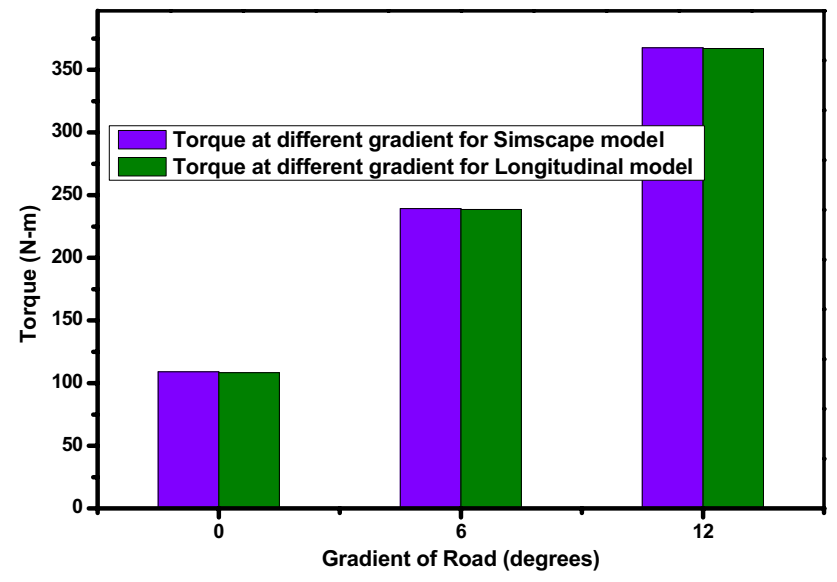

Fig. 7 Comparison of the torque values of the Simscape and longitudinal models for different gradient levels

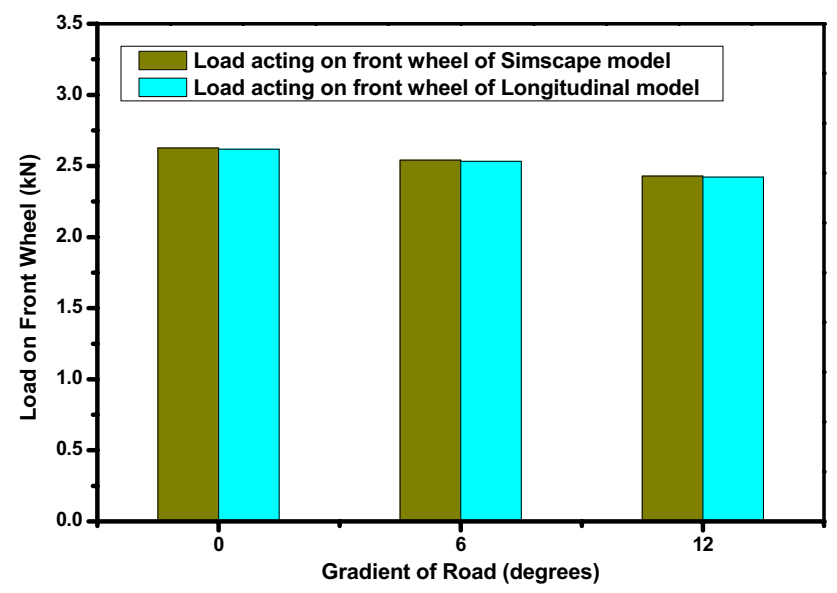

Fig. 8 Comparison in load acting on the front wheel values of the Simscape and longitudinal models for different gradient levels

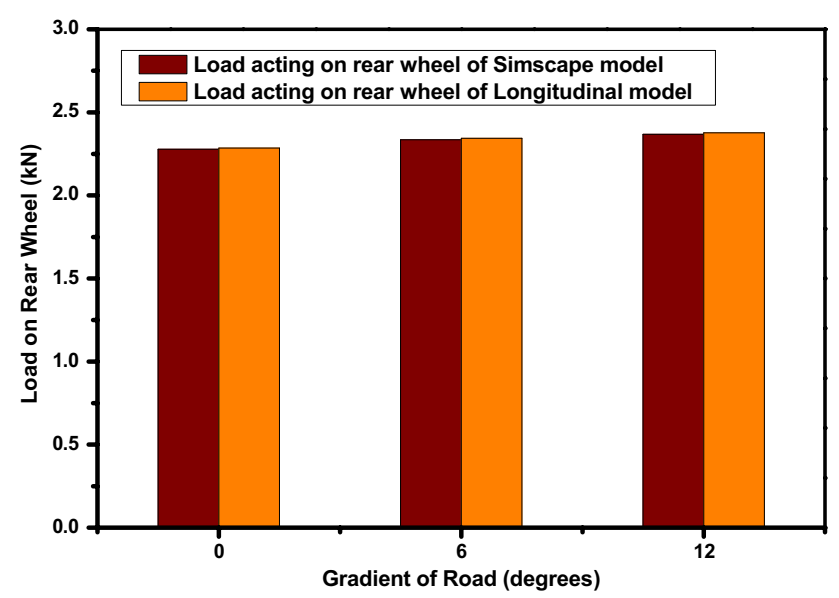

Fig. 9 Comparison in load acting on the rear axle values of the Simscape and longitudinal models for different gradient levels computed torque values of Simscape and longitudinal model are approximately the same for each gradient of the road.

Figure 8 shows the result values of the load acting on the front axle for Simscape and longitudinal model at the gradient levels of $0^{\circ}, 6^{\circ}$ and $12^{\circ}$ respectively. The difference between the result values of the load acting on the front wheel for Simscape and longitudinal model is negligible as depicted in the Fig. 8. Hence, the result values of the load acting on the front axle for Simscape and longitudinal model are approximately the same.

Result values of the load acting on the rear wheel for Simscape and longitudinal model at the gradient levels of $0^{\circ}, 6^{\circ}$ and $12^{\circ}$ respectively are shown in Fig. 9 . The difference between the result values of the load acting on the rear wheel for Simscape and longitudinal model is negligible as depicted in Fig. 9. Hence, the result values of the load acting on the rear axle for Simscape and longitudinal model are approximately the same.

Further, Table 4 shows the computing error/difference between the result values of the applied torques, the load acting on the front and the rear axles at each gradient level for Simscape and longitudinal model.

The difference/error between the applied torque of the Simscape model and tractive torque of longitudinal model are $0.7033,0.7218$ and 0.6347 for the gradient of $0^{\circ}, 6^{\circ}$ and $12^{\circ}$ respectively. Thus, the difference/error in torque value is very less, therefore applied torque of Simscape model is equal to the longitudinal model. The load acting on the front as well as rear axles of the Simscape physical model is approximately equal to the longitudinal vehicle model for the given road conditions.

It is concluded from the above analysis that the results of the Simscape model are same as the results of theoretical vehicle model for three gradient conditions of the road having a slope of $0^{\circ}, 6^{\circ}$ and $12^{\circ}$ respectively. Hence, the Simscape physical dynamics model of three-wheeled solar/battery electric vehicle designed and developed in the Simscape library tool is accurate and valid.

\section{Discussion}

Solar electric vehicles are considering as the "Green and Clean vehicles of the future" to meet the sustainable development goal. The discussion begins with modelling of the proposed solar electric vehicle prepared in SolidWorks ${ }^{\circ}$ tool. Next, the physical model of three-wheeled electric vehicle is designed in the Simscape tool. Now, this physical model is compiled in Simscape environment to crosscheck the errors. After that, simulations of the physical vehicle model have carried out for $10 \mathrm{~s}$ in the Simscape ${ }^{\circ}$ environment for the gradient of $0^{\circ}, 6^{\circ}$ and $12^{\circ}$ respectively. 
Table 4 The Comparison between Simscape and analytical model results

\begin{tabular}{|c|c|c|c|c|c|}
\hline \multirow[t]{2}{*}{ Road slope (a) } & \multicolumn{2}{|l|}{ Simscape physical model } & \multicolumn{2}{|c|}{ Longitudinal vehicle model } & \multirow[t]{2}{*}{ Error } \\
\hline & Variable's name & Numerical value & Variable's name & Numerical value & \\
\hline \multirow[t]{3}{*}{$0^{\circ}$} & Applied Torque & 109.035(N-m) & Tractive Torque & $108.3317(\mathrm{~N}-\mathrm{m})$ & 0.7033 \\
\hline & Load on the front axle & $2.627(\mathrm{kN})$ & Load on the front axle & $2.6188(\mathrm{kN})$ & 0.0082 \\
\hline & Load on the rear axle & $2.2782(\mathrm{kN})$ & Load on the rear axle & $2.2862(\mathrm{kN})$ & 0.0080 \\
\hline \multirow[t]{3}{*}{$6^{\circ}$} & Applied Torque & $239.18(N-m)$ & Tractive Torque & $238.4582(\mathrm{~N}-\mathrm{m})$ & 0.7218 \\
\hline & Load on the front axle & $2.5425(\mathrm{kN})$ & Load on the front axle & $2.5343(\mathrm{kN})$ & 0.0082 \\
\hline & Load on the rear axle & $2.3360(\mathrm{kN})$ & Load on the rear axle & $2.3438(\mathrm{kN})$ & 0.0078 \\
\hline \multirow[t]{3}{*}{$12^{\circ}$} & Applied Torque & 367.589(N-m) & Tractive Torque & $366.9543(\mathrm{~N}-\mathrm{m})$ & 0.6347 \\
\hline & Load on the front axle & $2.4295(\mathrm{kN})$ & Load on the front axle & $2.4215(\mathrm{kN})$ & 0.0080 \\
\hline & Load on the rear axle & $2.3684(\mathrm{kN})$ & Load on the rear axle & $2.3768(\mathrm{kN})$ & 0.0084 \\
\hline
\end{tabular}

Next, the dynamic performance of a three-wheeled vehicle for each road gradient is analysed.

The longitudinal vehicle mathematical model is developed for the three-wheeled vehicle to check and validate the Simscape model. The appropriate design parameters of the vehicle are selected as per the literature. Now, mathematical expressions of longitudinal vehicle model are coded in MATLAB ${ }^{\circ}$ coding environment. Next, the values of the tractive effort, the tractive torque acting on the wheel, the dynamic load acting on the front and rear axles are estimated from the coded equations. Finally, the Simscape vehicle model results are compared and validated with the longitudinal model.

\section{Limitation}

The following limitations are outlined for the solar threewheeled vehicle based on the results and discussion carried out in this article as given below:

(a) The range anxiety problem is severe due to the unavailability of sunlight due to adverse weather conditions for solar powered vehicles.

(b) In the developing countries like India, the unavailability of charging station is also a considerable concern for society to adopt the solar electric vehicles.

(c) Partial shading effect and air effect on PV modules of moving vehicles are also the obstacles to utilise of PV system with electric vehicles efficiently.

(d) Storage of solar Irradiations in lead-acid batteries is a huge concern due to the much lower specific energy of batteries compared to conventional fuel.

\section{Conclusion}

The physical vehicle model of three-wheeled having the configuration of two rears and one front wheel is designed and developed in the Simscape environment tool to analyse the gradient effect on dynamic performance. The Ideal torque source, differential gear, ideal rotational motion sensors, tire, vehicle body and ideal translation motion sensors etc. are the key physical blocks associated with the physical model of vehicle. This generated torque from ideal torque source is transferred to the differential and finally from differential gear to the left and right rear wheels of the vehicle to impart motion. The Simscape model results shows that the applied torque on the wheels is four-times more for gradient level of $12^{\circ}$ as compared to $0^{\circ}$. Mathematical vehicle model of a threewheeled vehicle is designed to analyse the accuracy of the Simscape physical vehicle model. Appropriate mechanical parameters and coefficients are selected from the literature for the simulations of the vehicle model. A comparison is undertaken between the results of the Simscape and longitudinal vehicle model for the road gradient of $0^{\circ}, 6^{\circ}$ and $12^{\circ}$ respectively. The results show the proposed Simscape physical model is acceptable and valid.

In the future, more research should be a focus on the solar/battery electric vehicle to make an eco-friendly environment. High specific energy storage batteries such as lithium-ion should be incorporated in the electric vehicles. Online monitoring and customisation system should be employed with solar vehicles to manipulate the PV module according to drive pattern. More solar recharging stations should be installed at parking lots, flyovers and roof areas to compensate for the driving range of electric vehicles.

Acknowledgements The authors would like to acknowledge the UGC and MNRE India for an assistant to support this research. 


\section{Compliance with ethical standards}

Conflict of interest The authors declare that they have no conflict of interest.

\section{References}

1. Yang S, Hong Z, Wei S, et al. (2014) Highly efficient solar energy vehicle design based on maximum power point tracking. In: 2014 international conference on information science, electronics and electrical engineering, IEEE, pp. 390-394. http:// ieeexplore.ieee.org/document/6948138/. Accessed 19 Feb 2018

2. Glouftsios $G$ (2018) Governing circulation through technology within EU border security practice-networks. Mobilities 13(2):185-199. https://doi.org/10.1080/17450101.2017.14037 74

3. Yun $H$, Zhao Y, Wang J (2012) Modeling and simulation of fuel cell hybrid vehicles. Int J Automot Technol 13(2):293-300. https ://doi.org/10.1007/s12239-012-0027-2

4. Qi L, Pan H, Zhu X et al (2017) A portable solar-powered aircooling system based on phase-change materials for a vehicle cabin. Energy Convers Manag 150:148-158

5. Digalwar AK, Giridhar G (2015) Interpretive structural modeling approach for development of electric vehicle market in India. Proc CIRP 26:40-45. http://linkinghub.elsevier.com/retrieve/pii/ S221282711400938X. Accessed 20 Feb 2018

6. Ashrafee F, Morsalin S, Rezwan A (2014) Design and fabrication of a solar powered toy car. In: 1st international conference on electrical engineering and information and communication technology, ICEEICT 2014

7. Society of India Automobile Manufacturers (SIAM) (2017) White paper on electric vehicles adopting pure electric vehicles : key policy enablers. http://www.siam.in/uploads/filemanager/114SI AMWhitePaperonElectricVehicles.pdf

8. Frieske B, Kloetzke M, Mauser F (2013) Trends in vehicle concept and key technology development for hybrid and battery electric vehicles. International Battery, Hybrid and Fuel Cell Electric Vehicle Symposium. pp 1-11. http://www.mdpi. com/1996-1073/9/8/596\%5Cn, http://www.mdpi.com/19961073/8/6/4697/\%5Cn, http://www.ep.liu.se/ecp_article/index .en.aspx?issue $=63$; article $=1 \% 5 \mathrm{Cn}$, http://www.maplecast.com $/$ Whitepapers/SeriesHEV_acmd2010.pdf\%5Cn, http://ieeexplore .ieee.org/lpdocs/epic0. Accessed 11 Oct 2017

9. Kumar L, Jain S (2014) Electric propulsion system for electric vehicular technology: A review. Renew Sustain Energy Rev 29:924-940

10. Khan S, Ahmad A, Ahmad F et al (2018) A comprehensive review on solar powered electric vehicle charging system. Smart Sci 6(1):54-79. https://doi.org/10.1080/23080477.2017.1419054

11. Hawkins TR, Singh B, Majeau-Bettez G et al (2013) Comparative environmental life cycle assessment of conventional and electric vehicles. J Ind Ecol 17(1):53-64. https://doi.org/10.111 1/j.1530-9290.2012.00532.x

12. Minh VT, Rashid VTM (2012) Modeling and model predictive control for hybrid electric vehicles. Int J Automot Technol 13(2):293-300. https://doi.org/10.1007/s12239-012-0027-2

13. Woo J, Choi H, Ahn J (2017) Well-to-wheel analysis of greenhouse gas emissions for electric vehicles based on electricity generation mix: A global perspective. Transp Res Part D Transp Environ 51: 340-350. http://linkinghub.elsevier.com/retrieve/ pii/S1361920916301973. Accessed 30 Aug 2018
14. Situ L (2009) Electric vehicle development: the past, present \& future. Power Electron Syst Appl 2009:1-3

15. Murakami H, Kataoka H, Honda Y, et al (2001) Highly efficient brushless motor design for an air-conditioner of the next generation $42 \mathrm{~V}$ vehicle. In: Conference record of the 2001 IEEE industry applications conference. 36th IAS Annual Meeting (Cat. No.01CH37248) 00(C): 461-466. http://ieeexplore.ieee.org/ Ipdocs/epic03/wrapper.htm?arnumber=955461. Accessed 11 Oct 2017

16. Na W, Park T, Kim T et al (2011) Light fuel-cell hybrid electric vehicles based on predictive controllers. IEEE Trans Veh Technol 60(1):89-97

17. Liu Y, Chen D, Lei Z, Qin D, Zhang Y, RWYL (2012) Modeling and control of engine starting for a full hybrid electric vehicle based on system dynamic characteristics. Int J Automot Technol 13(2):293-300. https://doi.org/10.1007/s12239-012-0027-2

18. Awais M, Anees M, Zaffar N (2017) Solar assisted, enhanced efficiency, induction motor EV drive with soft phase conversion. In: IECON 2017-43rd annual conference of the IEEE industrial electronics society. pp 2184-2189

19. Lv M, Guan N, Ma Y, et al (2016) Speed planning for solar-powered electric vehicles. In: Proceedings of the seventh international conference on future energy systems-e-Energy'16. pp 1-10. http://dl.acm.org/citation.cfm?doid=2934328.2934334. Accessed 9 Aug 2018

20. Tota A, Lenzo B, Lu Q, Sorniotti A, Gruber P, Fallah S, Velardocchia M, Galvagno E, De Smet J (2012) On the experimental analysis of integral sliding modes for yaw rate and sideslip control of an electric vehicle with multiple motors. Int J Automot Technol 13(2):293-300. https://doi.org/10.1007/s12239-012-0027-2

21. Mulhall P, Lukic SM, Wirasingha SG et al (2010) Solar-assisted electric auto rickshaw three-wheeler. IEEE Trans Veh Technol 59(5):2298-2307

22. Sameeullah M, Chandel S (2016) Design and analysis of solar electric rickshaw: A green transport model. In: 2016 international conference on energy efficient technologies for sustainability, ICEETS 2016, pp 206-211

23. Shaha N, Uddin MB (2013) Hybrid energy assisted electric auto rickshaw three-wheeler. In: 2013 international conference on electrical information and communication technology, EICT 2013

24. Tarek R, Anjum A, Hoque MA, et al (2016) Solar electric ambulance van unfolding medical emergencies of rural Bangladesh. In: GHTC 2016-IEEE global humanitarian technology conference: technology for the benefit of humanity, conference proceedings, pp 514-519

25. Tang X, Hu X, Yang W, et al (2018) Novel torsional vibration modeling and assessment of a power-split hybrid electric vehicle equipped with a dual-mass flywheel. In: IEEE transactions on vehicular technology 67(3): 1990-2000. http://ieeexplore.ieee. org/document/8094957/. Accessed 17 Apr 2018

26. Eshani M, Gao Y, Gay S, et al (2010) Modern electric, hybrid electric and fuel cell vehicles. In: Fundamentals, theory, and design. Power electronics and applications series, 2nd edn. CRC Press, New York. http://scholar.google.com/schol ar?hl=en\&btnG=Search\&q=intitle:Modern+Electric, + Hybri $\mathrm{d}+$ Electric,+and+Fuel+Cell+Vehicles\#1. Accessed 11 Oct 2017

27. National Research Council and Press TNA (2006) Tires and passenger vehicle fuel economy: Informing consumers, improving performance. Special Report 286

28. Hucho W, Sovran G (1993) Aerodynamics of road vehicles. Ann Rev Fluid Mech 25(1):485-537. https://doi.org/10.1146/annur ev.fl.25.010193.002413

29. Nandi AK, Chakraborty D, Vaz W (2015) Design of a comfortable optimal driving strategy for electric vehicles using multi-objective optimization. J Power Sour 283: 1-18. http://linkinghub 
.elsevier.com/retrieve/pii/S0378775315003547. Accessed 11 Oct 2017

30. Maia R, Silva M, Araujo R, et al. (2011) Electric vehicle simulator for energy consumption studies in electric mobility systems. In: 2011 IEEE forum on integrated and sustainable transportation systems, FISTS 2011, pp 227-232

31. ICAT (2018) Air density calculator. http://www.denysschen.com/ denysschen/catalogue/density.aspx. Accessed 10 Sept 2018

32. Asamer J, Graser A, Heilmann B et al (2016) Sensitivity analysis for energy demand estimation of electric vehicles. Transp Res Part D Transp Environ 46:182-199

33. Hayes JG, de Oliveira RPR, Vaughan S, et al (2011) Simplified electric vehicle power train models and range estimation. In: 2011 IEEE vehicle power and propulsion conference: 1-5. http://ieeexplore.ieee.org/lpdocs/epic03/wrapper.htm?arnum ber $=6043163$. Accessed 11 Oct 2017

34. I-cat (n.d.) E-Rickshaw/E-cart models approved as per GSR 709 (E) and SO 2590(E) dated 8th October 2014. https://www.icat. in/pdf/website_e-rickshaw. Accessed 10 Sept 2018
35. SAERA ELECTRIC AUTO PVT. LTD (n.d.). http://www.saeraelect ricauto.com/. Accessed 10 Sept 2018

36. Kuku Automotives - Manufacturer of Battery Operated Rickshaw; Battery Operated Three Wheeler from Jaipur (n.d.). http:// www.kukuautomotives.com/. Accessed 10 Sept 2018

37. Goenka Electric Motor Vehicles Private Limited, New Delhi (2018) Manufacturer of battery operated E-Rickshaw and electric delivery rickshaw (n.d.). http://www.goenkaelectric.com/. Accessed 10 Sept 2018

38. SuperECo Automotive Co. (n.d.). http://www.supereco.in/. Accessed 10 Sept 2018

Publisher's Note Springer Nature remains neutral with regard to jurisdictional claims in published maps and institutional affiliations. 